\title{
Re-Excision Rates in Breast-Conserving Surgery for Invasive Breast Cancer after Neoadjuvant Chemotherapy with and without the Use of a Radiopaque Tissue Transfer and X-ray System
}

\author{
Suniza Jamaris ${ }^{a}$ Leyla Akpolat-Basci ${ }^{b} \quad$ Miltiades Stephanou ${ }^{c}$ Sarah Wetzig ${ }^{c}$ \\ Yueksel Cubuk $^{d}$ Johannes Gerharz ${ }^{d}$ Ann-Kathrin Bittner ${ }^{\mathrm{e}}$ Mee Hoong See ${ }^{\mathrm{a}}$ \\ Cornelia Liedtke $^{f}$ Hans-Christian Kolberg ${ }^{c}$ \\ a Department of Surgery, Faculty of Medicine, University of Malaya, Lembah Pantai, Kuala Lumpur, Malaysia;

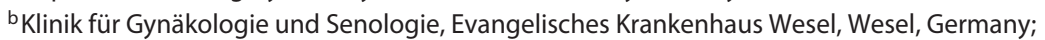 \\ 'Klinik für Gynäkologie und Geburtshilfe, Marienhospital Bottrop, Bottrop, Germany; \\ d Klinik für Radiologie, Marienhospital Bottrop, Bottrop, Germany; \\ eKlinik für Gynäkologie und Geburtshilfe, Universitätsklinikum Essen, Essen, Germany; \\ ${ }^{f}$ Klinik für Gynäkologie mit Brustzentrum, Charité - Universitätsmedizin Berlin, Berlin, Germany
}

\section{Keywords}

Specimen radiography $\cdot$ Klinitray ${ }^{\mathrm{TM}} \cdot$ Re-excision rate $\cdot$ Breast cancer · Breast-conserving surgery · Neoadjuvant chemotherapy

\section{Summary}

Background: Significant re-excision rates in breast-conserving surgery (BCS) after neoadjuvant systemic chemotherapy may result from difficulties in defining the surgical target particularly in cases with excellent treatment response. Devices allowing an exact topographic localisation of the lesion in the resected tissue could reduce re-excision rates by optimising the intraoperative detection of involved margins. Methods: 80 patients with invasive breast cancer receiving BCS after neoadjuvant chemotherapy were included in this non-randomized case-control study. 40 patients with specimen radiography performed in a standard approach (control group) were compared to 40 patients with use of a radiopaque tissue transfer system (study group). Results: 19/80 (23.75\%) patients required re-excision because of involved margins; among those, $14 / 40$ (35\%) were in the control group and $5 / 40(12.5 \%)$ in the study group. The association between the use of the radiopaque tissue transfer system and the lower re-excision rate was statistically significant $(p=0.023)$. Conclusion: Our analysis provides a rationale for the routine use of a

HCK and CL contributed equally to the submitted work. radiopaque tissue transfer system for specimen radiography in BCS after neoadjuvant chemotherapy for invasive breast cancer in order to reduce re-excision rates.

(c) 2018 S. Karger AG, Basel

\section{Introduction}

Breast conserving surgery (BCS) is a standard of care in the treatment of early breast cancer. There is a strong body of evidence from randomised trials supporting equivalent survival outcomes for mastectomy versus BCS plus radiotherapy in early breast cancer patients [1-3]. The basic principle of BCS is the complete removal of the tumour, preserving normal breast tissue with an acceptable cosmetic result. Negative margins are an essential component in this concept.

Historically, BCS has been commonly associated with high reexcision rates due to lack of guidelines to define optimal margin width. Achieving histopathologically negative margins is essential as it is one of the predictive factors for minimizing the risk of local recurrence. Positive resection margins may lead to unavoidable second surgery to re-excise margins or even to mastectomy. Published re-excision rates after BCS for invasive breast cancer vary between 10 and 50\% [4-7]. Re-excision for positive margins increases medical cost due to the second operation and affects patients in many ways including undergoing another general anaesthesia, the general risks of every surgery, and a possible loss of con-

\section{KARGER \\ Fax +497614520714

(c) 2018 S. Karger AG, Basel 


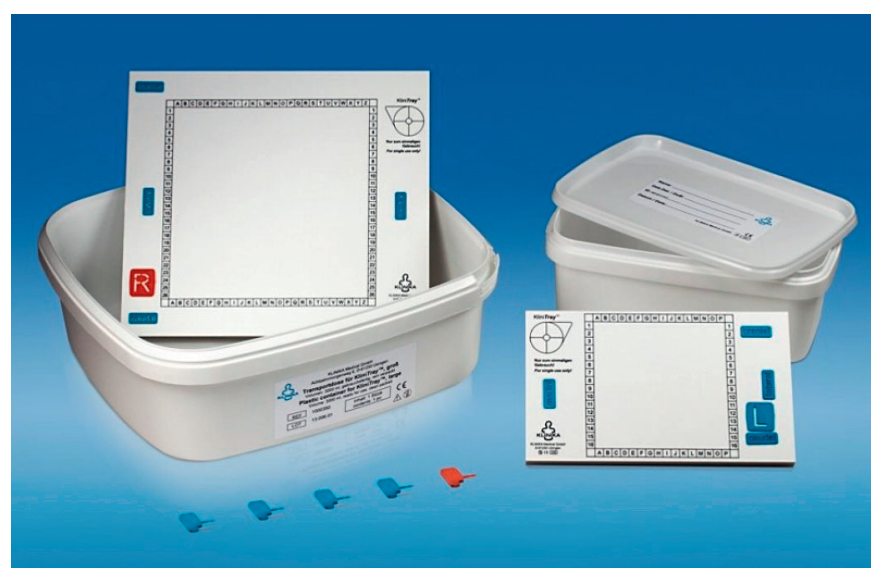

Fig. 1. Klinitray ${ }^{\mathrm{TM}}$.

fidence in a successful treatment. Furthermore, it may delay the start of adjuvant treatment and yield an unsatisfactory cosmetic outcome. The 2014 Society of Surgical Oncology-American Society for Radiation Oncology guidelines defined no tumour on ink as the standard for an adequate margin in invasive breast cancer. This definition is associated with low rates of ipsilateral breast tumour recurrence and has the potential to reduce second surgery or reexcision rates whilst improving cosmetic outcomes and decrease healthcare costs [8].

Neoadjuvant systemic therapy (NAST) represents a standard of care not only for inoperable or locally advanced breast cancers but also for smaller operable tumours. It is an option for all patients in whom systemic therapy is definitely indicated at the time of diagnosis with the goal of improving disease-free and overall survival [9] by potentially allowing response-guided treatment by in-vivo observation of chemotherapy sensitivity in an individual case. Regimens used in the neoadjuvant setting are usually the same as in adjuvant therapy.

Use of chemotherapy and especially neoadjuvant chemotherapy in HER2-positive and triple-negative breast cancer is common clinical practice, but patients with high-risk hormone receptorpositive HER2-negative disease with tumours showing a high proliferation rate or further risk factors such as grade 3 or high-risk classification based on a multigene assay may benefit from cytotoxic therapy and are therefore also potential candidates for neoadjuvant chemotherapy [10]. Achieving a pathologic complete response (pCR) is considered to indicate a favourable prognosis [11]. This has led to an increased use of NAST before breast surgery.

The intraoperative assessment of margins is a useful tool to avoid re-excision but remains challenging after NAST especially in patients with good response. Potential methods of intraoperative assessment of margins such as intraoperative frozen section, intraoperative specimen ultrasound, and intraoperative specimen radiography all have in common that they are aimed at a reduction in re-excision rates. In specimen radiography, defining the exact location of involved margins is often difficult due to the fact that standard approaches only include radiography in 2 planes and therefore no in-
Table 1. Patient characteristics

\begin{tabular}{llll}
\hline & $\begin{array}{l}\text { Klinitray } \\
(\mathrm{n}=40)\end{array}$ & $\begin{array}{l}\text { Standard } \\
(\mathrm{n}=40)\end{array}$ & $\mathrm{p}$ \\
\hline $\begin{array}{l}\text { Tumour size prior to neoadjuvant } \\
\begin{array}{c}\text { chemotherapy, mm } \\
\text { Residual ductal carcinoma in situ (DCIS) } \\
\text { only, n }\end{array}\end{array}$ & 21.8 & 21.65 & 0.911 \\
$\begin{array}{l}\text { Residual DCIS and invasive tumour, } \mathrm{n} \\
\text { Residual invasive tumour only, n }\end{array}$ & 21 & 9 & 0.796 \\
\hline
\end{tabular}

formation can be obtained regarding the 3-dimensional topography of the specimen. Devices allowing for horizontal and vertical examination and an exact topographic localisation of the lesion in the resected tissue could reduce re-excision rates via intraoperative detection and exact 3-dimensional localisation of involved margins. Here we present the results of a case-control study comparing re-excision rates after NAST using a standard specimen radiography versus a device allowing 3-dimensional radiography and exact topographic and reproducible localisation of the residual lesion.

\section{Material and Methods}

Patient Population

A total of 80 patients with invasive breast cancer receiving BCS after neoadjuvant chemotherapy and with an indication for wire marking by mammography were included in this analysis. We identified 320 consecutive patients with wire marking by mammography in our database between February 2013 and January 2017. 77 patients were excluded from the analysis because they were operated on for benign disease or non-invasive breast cancer. From the remaining 243 patients with invasive breast cancer, 163 were excluded because they received primary surgery and no neoadjuvant chemotherapy, had participated in clinical studies and had received investigational drugs, or had achieved a pCR. Of the remaining 80 patients, 40 were treated before the use of the Klinitray ${ }^{\mathrm{TM}}$ device (Faxitron, Tucson, AZ, USA) in our centre in April 2015 and 40 after that time point. The local ethics committee approved of the retrospective analysis on February 1, 2017. All tumours were marked with titanium clips prior to chemotherapy.

\section{Intervention}

In 40 patients, specimen radiography was performed in a standard approach (control group), and in 40 patients, a tissue transfer and X-ray system based on a non-radiopaque board with radiopaque topographic markers and a stand for cranio-caudal X-rays (Klinitray, fig. 1) was used (study group). Tumour size in $\mathrm{mm}$ prior to NAST was compared using the t-test. Categorical variables of residual ductal carcinoma in situ (DCIS) only, residual DCIS and invasive residual tumour, and residual invasive tumour only were compared using the chi-square and Fisher's exact test. A univariate analysis was carried out to evaluate the association between the use of the radiopaque tissue transfer system and the re-excision rate using a logistic regression model. Calculations were performed using the XLSTAT Biomed Software, version 19.03 (Addinsoft, New York, NY, USA).

\section{Results}

The study groups were well balanced. Mean age was 61 years (range 34-82 years) in the control group and 58 years (range 35-80 years) in the study group. Neoadjuvant chemotherapy was different according to tumour biology. Hormone receptor-positive HER2/ 
Fig. 2. Re-excision rates.

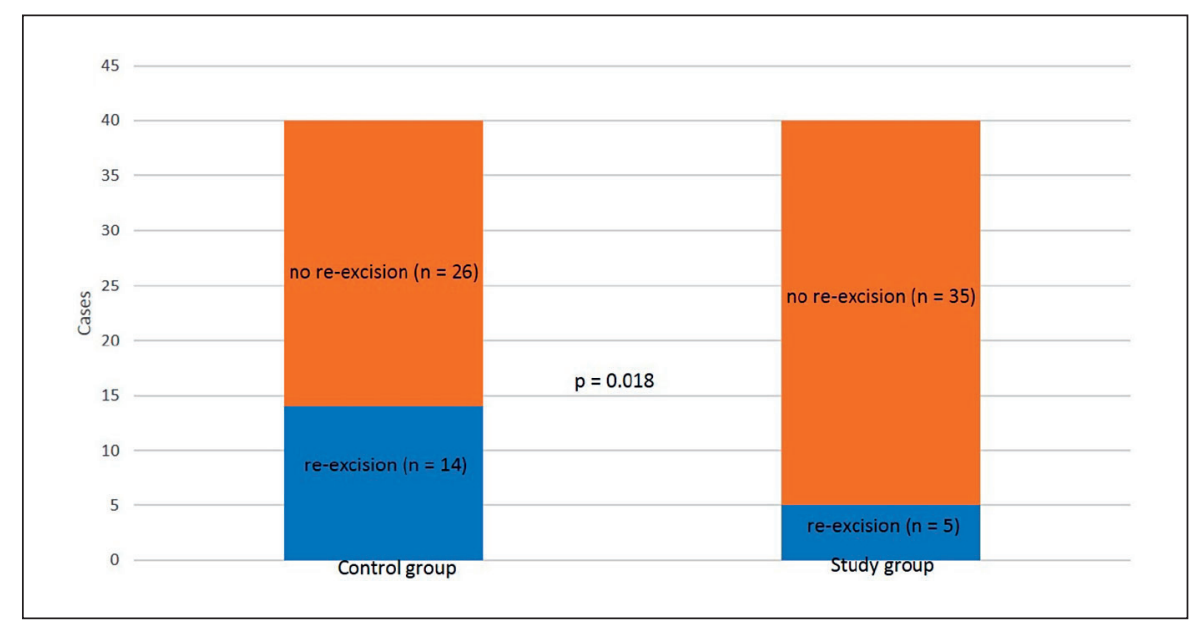

3

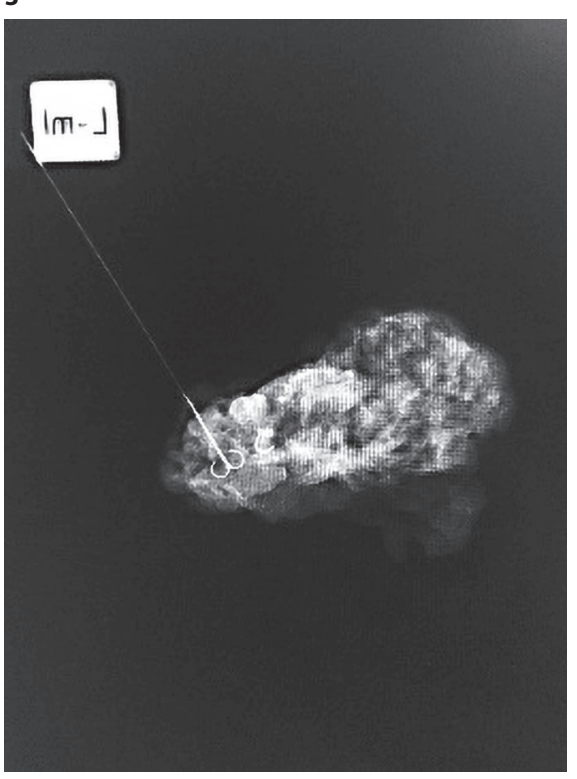

4

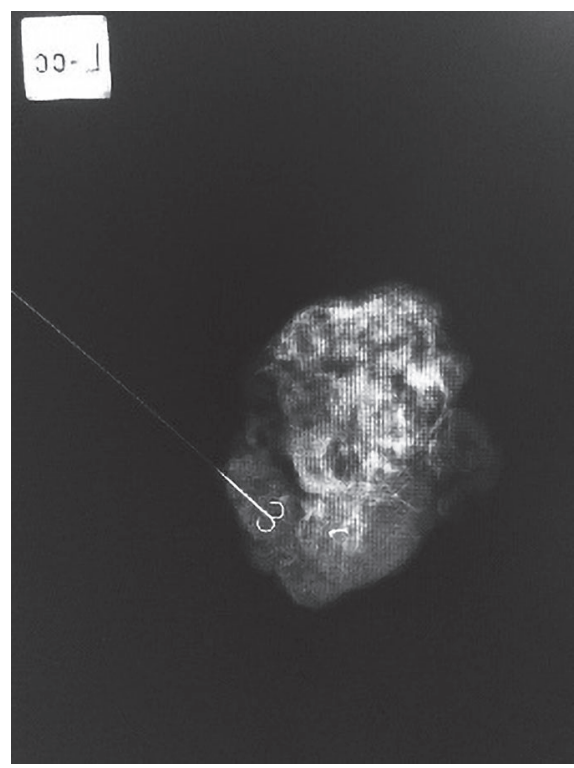

Fig. 3. Specimen radiography mediolateral (ML) projection control group.

Fig. 4. Specimen radiography craniocaudal (CC) projection control group.

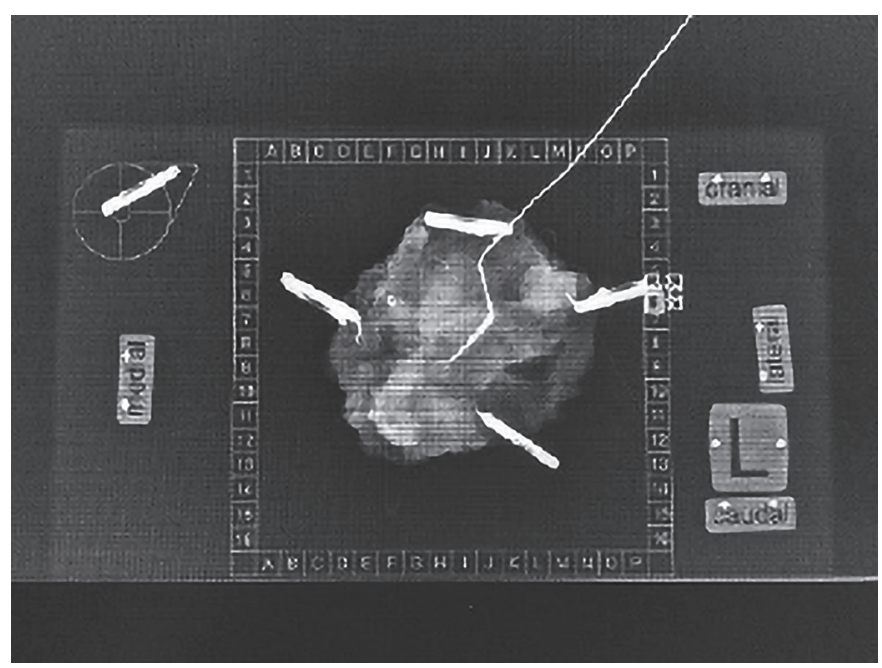

Fig. 5. Specimen radiography craniocaudal (CC) projection study group. neu-negative patients received 4 cycles of epirubicin and cyclophosphamide every 3 weeks ( $\mathrm{q} 3 \mathrm{w}$ ) followed by 12 cycles of paclitaxel q1w during the course of the analysis. HER2/neu-positive patients received 6 cycles of docetaxel, carboplatin, and trastuzumab $\mathrm{q} 3 \mathrm{w}$ until May 2015; from June 2015, pertuzumab q3w was added to this regimen. Triple-negative patients received 4 cycles of epirubicin and cyclophosphamide $\mathrm{q} 3 \mathrm{w}$ followed by 12 cycles of paclitaxel $\mathrm{q} 1 \mathrm{w}$ until December 2015, since January 2016 carboplatin q1w was added. Patient characteristics relevant for this analysis are shown in table 1. 19/80 (23.75\%) patients required re-excision because of involved margins; among those, 14/40 (35\%) were in the control group and $5 / 40(12.5 \%)$ in the study group (fig. 2). The association between the use of the radiopaque tissue transfer system and the lower re-excision rate was statistically significant $(p=0.023)$. The different visualization of the specimen in the control group and the study group using the Klinitray is shown in figures 3-7. 
Fig. 6. Specimen radiography oblique projection study group.

Fig. 7. Specimen radiography mediolateral (ML) projection study group.

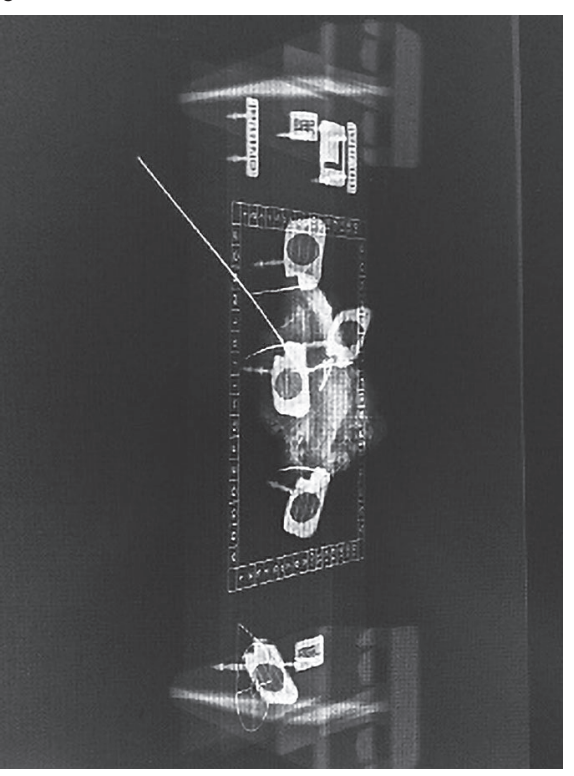

7

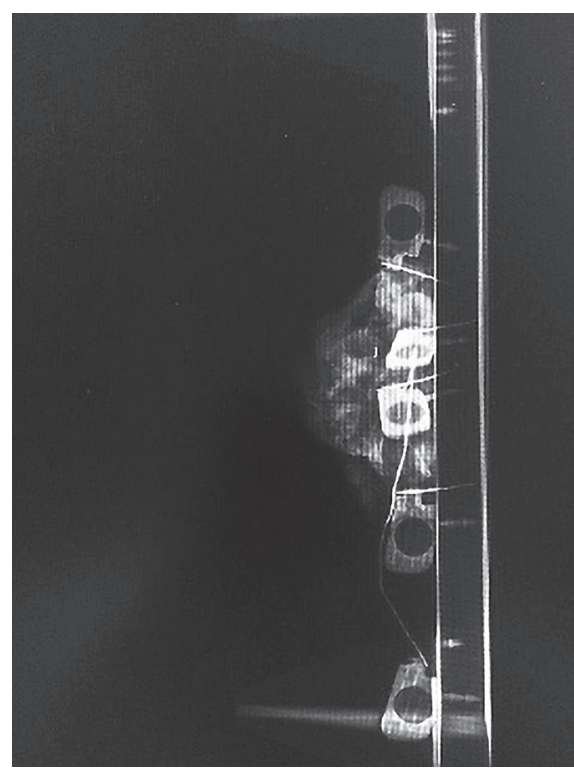

\section{Discussion}

NAST in breast cancer has traditionally been used in locally advanced cases in order to allow BCS. During the last decade, the rates of NAST have steadily increased since it is increasingly regarded as representing the standard of care in cases in whom an indication for adjuvant chemotherapy is evident at the time of diagnosis [12]. As in every systemic treatment, this approach is aimed at achieving local control and increasing overall survival. A recent meta-analysis by the Early Breast Cancer Trialists' Collaborative Group (EBCTG) including 4,756 women from 10 randomized trials in early breast cancer found that NAST was associated with a higher local recurrence rate than adjuvant chemotherapy: the 15-year local recurrence was $21.4 \%$ for NAST versus $15.9 \%$ for adjuvant chemotherapy (increase by $5.5 \%$, 95\% confidence interval (CI) 2.4-8.6; rate ratio $1.37,95 \%$ CI $1.17-1.61 ; \mathrm{p}=0.0001$ ). Interestingly, the higher local recurrence was not significantly associated with distant recurrence and breast cancer mortality [13]. It remains questionable whether the results of this meta-analysis apply to the current situation because only trials with a follow-up of 15 years were included, thus representing the treatment paradigm on the threshold of the new millennium when only patients with locally advanced tumours were candidates for NAST, whereas currently the indication for NAST is usually based on tumour biology and not on clinical tumour stage. Furthermore, not all patients underwent surgery, instead some were treated with radiotherapy alone.

Achieving negative margins during only 1 surgical procedure may be more challenging after compared to before NAST. Study results regarding this subject vary. In a retrospective study, a similar re-excision rate was reported comparing patients undergoing primary surgery and patients after NAST $(35.6 \%$ in NAST group vs. $35.6 \%$ in non-neoadjuvant group; $\mathrm{p}=1.000$ ) [14]. This result was in line with another analysis demonstrating a similar incidence of positive margins after NAST and primary surgical treatment [15]. A third study reported that only $6 \%$ in the NAST group had positive margins and required re-excision compared to $37 \%$ in the surgery first group $(\mathrm{p}<0.01)[16]$. However, the analysis of a large cohort of 9,901 patients observed $10.2 \%$ involved margins in primary surgery patients and $24.3 \%$ involved margins after NAST. The adjusted odds ratio for involved margins after NAST was 2.94, translating into a 3 times higher risk of involved margins compared to primary surgery [17].

Theoretically, local recurrence rates could be influenced by the presence of DCIS not responding to cytotoxic chemotherapy. Furthermore, not all tumours show a concentric shrinkage, instead response may also result in a disseminated tumour pattern in the breast. Both residual DCIS and disseminated tumour are challenging to the goal of complete excision of the tumour as they are neither palpable nor easily detectable with techniques of intraoperative imaging [18].

However, clear margins remain a major prognostic factor. In 34 studies reviewed for margin status and local recurrence, persistent microscopically inadequate (R1) or macroscopically inadequate (R2) surgical margins were highly significant for local recurrence compared with negative margins $(\mathrm{p}=0.0001)$, depicting the relevance of margin status to local control after BCS [19]. An informative intraoperative assessment of margins is crucial to reduce the risk of local recurrence. Although failure to excise adequate margins during the first operation may be rectified by re-excision, this can affect patients in many ways including higher rates of wound infection and additional risks of surgery and general anaesthesia and increases the overall costs of treatment.

One of the most common imaging techniques for surgical specimen evaluation and assessment of adequate margins is standard specimen radiography. However, the diagnostic performance of standard specimen radiography varies widely, with sensitivity ranging from 30 to $66 \%$ [20-22]. In a retrospective study, standard 
radiologic specimen examination did not improve the rates of histologically clear margins, especially not in non-palpable in situ carcinoma [23]. In another retrospective analysis, specimen radiography proved to be reliable in identifying the target lesion; however, margin orientation compared to final pathology was far less reliable [24]. In contrast, specimen radiography in 2 orthogonal views and with direct magnification was reported to be reliable in identifying clear margins with a positive predictive value of $74 \%$ and a negative predictive value of $81 \%$ [21]. Another study using 2-view specimen mammography demonstrated a reduced reoperation rate of $5 \%$ compared to $12 \%$ by identifying patients requiring additional margin excision at the time of initial surgery during BCS [25].

Intraoperative digital specimen radiography is another widely used approach to assess resection margins during BCS. The mammography device is placed adjacent to or even in the operating theatre, thus reducing transportation time and facilitating a cooperative assessment by the surgeon and the radiologist. Compared to standard specimen radiography, intraoperative digital specimen radiography significantly reduces interpretation times and increases accurate identification of the target, resulting in decreased healthcare costs due to shorter operation times [26]. Additionally, intraoperative digital specimen radiography improves the organisation of the intraoperative workflow and the management of human resources [27] and leads to fewer positive margins after BCS [28].

Intraoperative specimen ultrasound is another technique improving the achievement of acceptable margins during BCS. Positive margin rates of between 3 and $11 \%$ have been reported for this approach [29-32]. However, intraoperative specimen ultrasound is only applicable in the case of lesions detectable by ultrasound, thus excluding microcalcifications and the majority of DCIS.

Radio-guided occult lesion localisation (ROLL) identifying the target lesion marked with a radioactive seed with a gamma probe has gained popularity over the past 20 years as the smaller volume of the specimen results in better cosmetic outcomes compared to wire-guided localisation, and, additionally, the rate of positive margins is significantly reduced [33, 34]. However, this technique does not allow intraoperative assessment of margins, focussing instead on the identification of the target.

Lately, new devices for intraoperative margin assessment have been introduced. ClearEdge ${ }^{\mathrm{TM}}$ (LS BioPath, Saratoga, CA, USA) is able to identify abnormal tissue including invasive cancer, DCIS, lobular carcinoma in situ, and atypical proliferative breast disease by bio-impedance spectroscopy, resulting in a re-excision rate of 7\% [35]. MarginProbe ${ }^{\mathrm{TM}}$ (Dune Medical Devices, Alpharetta, GA, USA), another device using the same principle, was reported to result in a reduction in reoperation rates by $56 \%[36,37]$.

Summarizing the data published to date, it is clear that optimal approaches to achieve clear margins in BCS remain a major scientific concern, especially after neoadjuvant therapy. Re-excision rates do not only have an impact on cosmetic outcome and affect patients psychologically but also increase healthcare costs. A cost analysis using Medicare reimbursement rates reported an increase of USD 18.8 million in healthcare costs per year through reoperations for positive margins in BCS in the United States. This calculation only included surgical costs for reoperations and excluded the costs of surgical complications after repeated surgery, thus potentially underestimating the possible savings achievable by avoiding reoperations for positive margins [38].

In our study, we could demonstrate a significant reduction in re-excision rates by $35 \%$ using a radiopaque tissue transfer system. In our analysis, neoadjuvant regimens included more agents in the study group in triple-negative and HER2/neu-positive breast cancer cases, but due to the fact that we excluded patients with pCR and given the purely technical focus of our investigation, we are confident that this did not influence our results. Furthermore, we are aware that the rather small sample size and the retrospective study design are limitations of our study. Despite these limitations, we believe our results to be clinically meaningful. The radiopaque tissue transfer system Klinitray is allowing identification of target lesions and margins in 2 orthogonal views with millimetre precision and is in compliance with international guidelines such as the National Health Service Breast Screening Programme (NHSBSP) [39]. The device is not only technically easy to handle but via integrated comprehensive markings also allows exact topographic localisation of the specimen. Importantly, the device does not require a special mammography unit but is compliant with mammography units already in use at our institution. Costs of little over EUR 20 per device are discriminating the Klinitray from the bio-impedance spectroscopy devices mentioned above.

\section{Conclusion}

Our analysis provides a rationale for the use of a radiopaque tissue transfer system for specimen radiography in BCS after neoadjuvant chemotherapy for invasive breast cancer in order to reduce re-excision rates. Based on these results, we are planning a study including also patients receiving primary surgery.

\section{Acknowledgement}

There has been no funding from any outside source for the submitted work.

\section{Disclosure Statement}

The authors declare that they have no relevant conflict of interest with regard to the presented work. 


\section{References}

1 Fisher B, Anderson S, Bryant J, Margolese RG, Deutsch M, Fisher ER, Wolmark N: Twenty-year follow-up of a randomized trial comparing total mastectomy, lumpectomy, and lumpectomy plus irradiation for the treatment of invasive breast cancer. N Engl J Med 2002;347:1233-1241.

- Jatoi I, Proschan MA: Randomized trials of breastconserving therapy versus mastectomy for primary breast cancer: a pooled analysis of updated results. Am J Clin Oncol 2005;28:289-294.

3 Van der Hage JA, Putter H, Bonnema J, Bartelink H, Therasse P, van de Velde CJ: Impact of locoregional treatment on the early-stage breast cancer patients: a retrospective analysis. Eur J Cancer 2003;39:21922199.

4 Aziz D, Rawlinson E, Narod SA, Sun P, Lickley HL, McCready DR, Holloway C: The role of re-excision for positive margins in optimizing local disease control after breast-conserving surgery for cancer. Breast J 2006;12:331-337.

5 Talsma AK, Reedijk AM, Damhuis RA, Westenend PJ, Vles WJ: Re-resection rates after breast-conserving surgery as a performance indicator: introduction of a case-mix model to allow comparison between Dutch hospitals. Eur J Surg Oncol 2011;37:357-363.

6 Jacobson AF, Asad J, Boolbol SK, Osborne MP, Boachie-Adjei K, Feldman SM: Do additional shaved margins at the time of lumpectomy eliminate the need for re-excision? Am J Surg 2008; 196:556-558.

7 Dubrovsky E, Chun J, Schwartz S, Guth A, Axelrod DM, Schnabel FR: Breast conserving surgery and reexcision rates: a single-institution's experience. J Clin Oncol 2017;35:181.

8 Moran MS, Schnitt SJ, Giuliano AE, Harris JR, Khan SA, Horton J, Johnson PL: Society of Surgical Oncology-American Society for Radiation Oncology consensus guideline on margins for breast-conserving surgery with whole-breast irradiation in stages I and II invasive breast cancer. Int J Radiat Oncol Biol Phys 2014;88: 553-564.

9 Kaufmann M, von Minckwitz G, Mamounas EP, Cameron D, Carey LA, Cristofanilli M, Denkert C, Eiermann W, Gnant M, Harris JR, Karn T, Liedtke C, Mauri D, Rouzier R, Ruckhaeberle E, Semiglazov V, Symmans WF, Tutt A, Pusztai L: Recommendations from an international consensus conference on the current status and future of neoadjuvant systemic therapy in primary breast cancer. Ann Surg Oncol 2012;19: 1508-1516.

10 Liedtke C, Hatzis C, Symmans WF, Desmedt C, HaibeKains B, Valero V, Kuerer H, Hortobagyi GN, PiccartGebhart M, Sotiriou C, Pusztai L: Genomic grade index is associated with response to chemotherapy in patients with breast cancer. J Clin Oncol 2009;27: 3185-3191.

11 Huober J, von Minckwitz G, Denkert C, Tesch H, Weiss E, Zahm DM, Belau A, Khandan F, Hauschild M, Thomssen C, Högel B, Darb-Esfahani S, Mehta K, Loibl S: Effect of neoadjuvant anthracycline-taxanebased chemotherapy in different biological breast cancer phenotypes: overall results from the GeparTrio study. Breast Cancer Res Treat 2010;124:133-140.

$\checkmark 12$ Liedtke C, Thill M, Jackisch C, Thomssen C, Müller V, Janni W: AGO recommendations for the diagnosis and treatment of patients with early breast cancer: update 2017. Breast Care (Basel) 2017;12:172-183.
McGale P, Dodwell D, Gray R, Mannu G, Peto R, Taylor C, Wang Y, Davies C, Bradley R, Braybrooke J, Pan $\mathrm{H}$ : Long-term outcomes for neoadjuvant versus adjuvant chemotherapy in early breast cancer: meta-analysis of individual patient data from ten randomised trials. Lancet Oncol 2018;19:27-39.

14 Song JH, Park JY, Choi JE, Kang S, Lee SJ, Bae Y: Reexcision rate in breast conservation surgery after neoadjuvant chemotherapy. J Breast Dis 2017;5:16-22.

15 Soucy G, Bélanger J, Leblanc G, Sideris L, Drolet P, Mitchell A, Leclerc YE, Dufresne MP, Beaudet J, Dubé $\mathrm{P}$ : Surgical margins in breast-conservation operations for invasive carcinoma: does neoadjuvant chemotherapy have an impact? J Am Coll Surg 2008;206:11161121.

16 Christy CJ, Thorsteinsson D, Grube BJ, Black D, AbuKhalaf M, Chung GG, DiGiovanna MP, Miller K, Higgins SA, Weidhaas J, Harris L, Tavassoli FA, Lannin DR: Preoperative chemotherapy decreases the need for re-excision of breast cancers between 2 and $4 \mathrm{~cm}$ diameter. Ann Surg Oncol 2009;16:697-702.

17 Volders JH, Haloua MH, Krekel NM, Negenborn VL, Barbé E, Sietses C, Jóźwiak K, Meijer S, van den Tol MP: Neoadjuvant chemotherapy in breast-conserving surgery: consequences on margin status and excision volumes: a nationwide pathology study. Eur J Surg Oncol 2016;42:986-993.

18 Redden MH, Fuhrman GM: Neoadjuvant chemotherapy in the treatment of breast cancer. Surg Clin North Am 2013;93:493-499.

19 Singletary SE: Surgical margins in patients with earlystage breast cancer treated with breast conservation therapy. Am J Surg 2002;184:383-393.

20 Saarela, AO, Rissanen TJ, Lähteenmäki KM, Soini Y, Haukipuro K, Kaarela O, Kiviniemi HO: Wire-guided excision of non-palpable breast cancer: determinants and correlations between radiologic and histologic margins and residual disease in re-excisions. Breast 2001;10:28-34.

21 Ciccarelli G, Di Virgilio MR, Menna S, Garretti L, Ala A, Giani R, Bussone R, Canavese G, Berardengo E: Radiography of the surgical specimen in early stage breast lesions: diagnostic reliability in the analysis of the resection margins. Radiol Med 2007;112:366-376.

22 Fouché CJ, Tabareau F, Michenet P, Lebas P, Simon EG: Specimen radiography assessment of surgical margins status in subclinical breast carcinoma: a diagnostic study. J Gynecol Obstet Biol Reprod (Paris) 2011;40: 314-322.

23 Rua C, Lebas P, Michenet P, Ouldamer L: Evaluation of lumpectomy surgical specimen radiographs in subclinical, in situ and invasive breast cancer, and factors predicting positive margins. Diagn Interv Imaging 2012;93:871-877.

24 Britton PD, Sonoda LI, Yamamoto AK, Koo B, Soh E, Goud A: Breast surgical specimen radiographs: how reliable are they? Eur J Radiol 2011;79:245-249.

25 McCormick JT, Keleher AJ, Tikhomirov VB, Budway RJ, Caushaj PF: Analysis of the use of specimen mammography in breast conservation therapy. Am J Surg 2004;188:433-436.

26 Miller CL, Coopey SB, Rafferty E, Gadd M, Smith BL, Specht MC: Comparison of intra-operative specimen mammography to standard specimen mammography for excision of non-palpable breast lesions: a randomized trial. Breast Cancer Res Treat 2016;155:513519.
7 Vicko F, Radovanović Z, Kapicl TI, Djilas D, Lukić D, Tatić M, Petrović T: Intraoperative digital specimen radiography in the treatment of nonpalpable breast lesions. Srp Arh Celok Lek 2017;145:378-381.

28 Kim SH, Cornacchi SD, Heller B, Farrokhyar F, Babra M, Lovrics PJ: An evaluation of intraoperative digital specimen mammography versus conventional specimen radiography for the excision of nonpalpable breast lesions. Am J Surg 2013;205:703-710.

29 Ngô C, Pollet AG, Laperrelle J, Ackerman G, Gomme S, Thibault F, Fourchotte V, Salmon RJ: Intraoperative ultrasound localization of nonpalpable breast cancers. Ann Surg Oncol 2007;14:2485-2489.

30 Bennett IC, Greenslade J, Chiam H: Intraoperative ultrasound-guided excision of nonpalpable breast lesions. World J Surg 2005;29:369-374.

31 Rahusen FD, Bremers AJ, Fabry HF, van Amerongen AH, Boom RP, Meijer S: Ultrasound-guided lumpectomy of nonpalpable breast cancer versus wire-guided resection: a randomized clinical trial. Ann Surg Oncol 2002;9:994-998.

32 Moore MM, Whitney LA, Cerilli L, Imbrie JZ, Bunch M, Simpson VB, Hanks JB: Intraoperative ultrasound is associated with clear lumpectomy margins for palpable infiltrating ductal breast cancer. Ann Surg 2001; 233:761-768.

33 Ocal K, Dag A, Turkmenoglu O, Gunay EC, Yucel E, Duce MN: Radioguided occult lesion localization versus wire-guided localization for non-palpable breast lesions: randomized controlled trial. Clinics (Sao Paulo) 2011;66:1003-1007.

34 Machado RH, Oliveira AC, Rocha AC, Landesmann MC, Martins FP, Lopes SA, Gutfilen B, da Fonseca LM: Radioguided occult lesion localization (ROLL) and excision of breast lesions using technetium-99m-macroaggregate albumin and air injection control. J Exp Clin Cancer Res 2007;26:323-327.

35 Dixon JM, Renshaw L, Young O, Kulkarni D, Saleem T, Sarfaty M, Sreenivasan R, Kusnick C, Thomas J, Williams LJ: Intra-operative assessment of excised breast tumour margins using ClearEdge imaging device. Eur J Surg Oncol 2016;42:1834-1840.

36 Karni T, Pappo I, Sandbank J, Lavon O, Kent V, Spector R, Morgenstern S, Lelcuk S: A device for real-time, intraoperative margin assessment in breast-conservation surgery. Am J Surg 2007;194:467-473.

37 Allweis TM, Kaufman Z, Lelcuk S, Pappo I, Karni T, Schneebaum S, Spector R, Schindel A, Hershko D, Zilberman M, Sayfan J, Berlin Y, Hadary A, Olsha O, Paran H, Gutman M, Carmon M: A prospective, randomized, controlled, multicenter study of a real-time, intraoperative probe for positive margin detection in breast-conserving surgery. Am J Surg 2008; 196:483489.

38 Abe SE, Hill JS, Han Y, Walsh K, Symanowski JT, Hadzikadic-Gusic L, Flippo-Morton T, Sarantou T, Forster M, White RL Jr: Margin re冈excision and local recurrence in invasive breast cancer: a cost analysis using a decision tree model. J Surg Oncol 2015;112: 443-448.

39 Ellis I, Al-Sam S, Anderson N, Carder P, Deb R, Girling A, Hales S, Hanby A, Ibrahim M, Lee AH, Liebmann R: Pathology Reporting of Breast Disease in Surgical Excision Specimens Incorporating the Dataset for Histological Reporting of Breast Cancer. London, The Royal College of Pathologists, 2016. Google Scholar. 